\title{
Art and technology: Contriving the future
}

\author{
Sukrit Sarkar ${ }^{1}$, Mugdha $^{2}$ \\ ${ }^{I}$ (CSE Department, College/ SRM University, India) \\ ${ }^{2}$ (ECE Department, College/ SRM University, India)
}

\begin{abstract}
The present paper discusses the initiatives taken by the Dot Org to address the prevalent issues of creativity crisis and lack of economic self-sufficiency. Dot Org is a non-government organization formed by undergraduate students of a technical college, who take out some time from their busy study schedule to contribute for the enhancing art skills of unprivileged children by imparting them education and raising funds for them. It further discusses how the evolution in the field of graphic designing has led to the devaluation of handmade arts and how one can combine the two to ensure the coexistence and development of both. The paper also shows the workflow showing implementation of the idea of creating a bridge between privileged and the underprivileged for sustainable development. The workflow includes the process of extraction of design, processing and then final publishing of the design in the form of an economic product.
\end{abstract}

Keywords - Art and Culture, Awareness, Sustainable Development, Self-Sustenance, Social Work.

\section{INTRODUCTION}

Art is the essence of life. Andre Maurois, a French author, has very rightly quoted that "Art is an effort to create, beside the real world, a more humane world". It's a medium to express our thoughts and feelings that can't be put into words, and because of art that we know how in the past people lived their lives. In today's time, people are losing their touch with their creative sides. In this rush to make money, many instead of thinking out of the box, follow mainstream set trends.

India has the world's largest youth population according to latest census 2011 data; almost 41 percent of the population is below the age of 20 years [3]. This overall calls for more employment and sustainable development. It is important to give the energy and brilliance of the youth a right outlet and engaging them in activities which will help in their overall development and productivity.

Art is a very powerful tool that can be used in a number of ways to change lives of people. All that's required is an effort to bring this change. Dot Org is a student run organization that does just that. They aim at creating a society where creative minds are given the freedom and opportunity to flourish and are given a chance to showcase their talent.

Their idea was to introduce and reinforce the importance of art and refurbish divergent thinking amongst the youth and the underprivileged of our country. The program started off in July 2015 and in this 14 months journey, has covered 3 major cities in India.

While collecting data, it was also noted that the children belonging to the underprivileged section of our society suffered majorly due to lack of opportunities that are provided to them. To ensure that the less privileged too got the opportunities to learn, the team, held free weekly art education classes in orphanages to help children develop and learn new skills. The handicrafts generated are then sold to conduct a fundraising project for the same orphanage.

When digged deeper into the subject of education, it was found that the teaching methods in schools focused more on providing children theoretical knowledge and pen and paper based examination methods. The methods had just a paucity of creativity and innovation in them [1]. Most of the ways that the children are taught nowadays haven't been changed since a decade or more. Not only do they restrict the thinking of the children, they also in a way restrict them from following their passion.

In some cases it was noted that there was a severe lack of support for children who wish to pursue a career line which is not a mainstream one from the parents as well as the teachers in their schools.

The teachings and guidance that the children get at an early age plays a major role in their lives. For instance, a child, if supported and guided properly, is more likely to succeed than a child who is not and is subdued or pressurized to fit a certain mold [7].

While teaching the kids in the orphanage it was observed that the children despite having potential, were helpless due to lack of money and support [4]. 
To help with this issue, new ways of teachings which are creative and support the children could be incorporated. Methods which would help kids realize their true potential and would help end the creativity crisis along with creating a sustainable future for them should be brought in use.

The organization also provides free seminars and workshops in various schools and institution based on awareness on web, exercise designing aspects and try to push them beyond conventional boundaries. The workflow of all the tasks handled is shown in Fig.1.

\section{METHODOLOGY}

In order to tackle this major setbacks prevailing in society it was a need of a group of like-minded people to take a initiative and have a proper methodology to tackle the above. The study for this paper was carried out on a student run organization, Dot Org. The organization is based on the sole purpose of bridging the gap between the privileged and the underprivileged and improving the involvement of youth in the activities that need creativity. The organization started its work with their first step was to form a small unit of people in a neighborly located orphanage. To do this task, the team was divided into two parts, the management and creative team.

\subsection{C: Drive}

Just like in a computer, where C:Drive is it's main drive and without it the system can't function, similarly, the organisation cannot function without its C:Drive team. The team handles the finances, marketing, and relations with the other organizations and people ready to help. This team reaches out to the schools and NGOs to conduct workshops and classes, and maintains the public relations. They also keep a track record of the work done by all the members of the organization and the sales and marketing of their products (Fig.1 [5]).

\section{2. $\mathrm{D}^{2} \mathrm{C}$}

The terms $\mathrm{D}^{2} \mathrm{C}$ stands for Dig, Design and Create. It means that the team digs out the recent trends in the market of designing and then meticulously designs the covers using the artworks. The team works on designing a curriculum which is suitable for the children and at the same time helps in their development and supplementing the learning that they get in the local schools(Fig.1[1,2]).

\subsection{Workflow}

The workflow of all the tasks handled is shown in Fig.1.

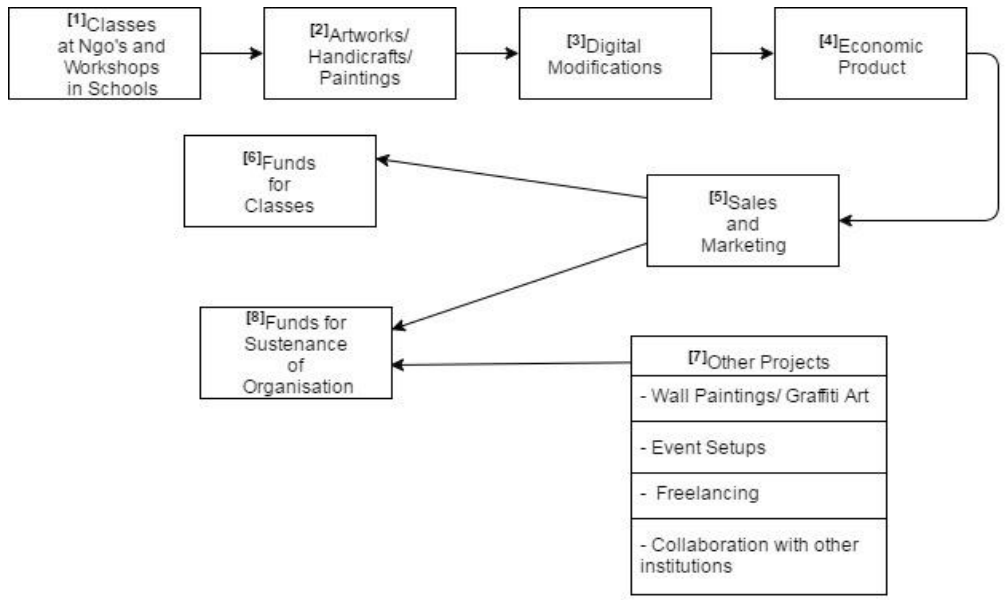

Fig.1. Workflow Table

\section{CHALLENGES}

The main challenge that the organization faced was putting the plans drawn on the paper into action. After reaching out to several other organizations and people, they got the permission to conduct their first class with Christ Faith Home, which is an orphanage for girls. The team took free of cost weekly art classes for the children there, and imparted several skills and values to the children .The biggest challenge that the organization faced was collecting the funds. It was important to keep the funds coming to arrange the supplies needed for the art classes (Fig.1 [6,8]). Instead of striving on donations, they reached out to several restaurants and local food joints, and offered to design their menu cards or paint their walls with customized designs. The local search landed them their first offer to paint a wall at a food joint, Kapaõ (Fig.1 [6]). The designs are made by the 
members of the creative team and the charges are fixed depending on the area of the wall, complexity of the design, materials, labor and the time required to finish the task.

\subsection{Daan Utsav}

IV.

PROJECTS

Daan Utsav which was earlier known as Joy of giving week, is a "festival of philanthropy" celebrated by organizing volunteering and fundraising events that aims at inspiring people to give- money, time, resources and skills. Dot Org celebrated the Daan Utsav by collaborating with Christ Faith Home, Chennai. The banners and the props were all designed by the team. The members volunteered to raise the funds and spread awareness by distributing pamphlets and cards designed by the orphanage children at a number of petrol pumps in Chennai.

\subsection{Awareness Campaigns}

A number of seminars and workshops were conducted by the team in some of the major cities across the country for the benefit of the children by collaborating with Adore India, Giving Back to the Society, Mozilla, and Bagheera Project, Christ Faith Home [5], to teach the kids about the web. The curriculum consists of vast area of topics including both technical and art and crafts.

\subsubsection{Creative Art}

The children were taught card making and were indulged in another methods to bring out their best creative sides like, collage making, painting without brushes, digital designing which included giving them a basic knowledge about Photoshop, MS Paint, Dreamweaver, Adobe Muse ,etc.

\subsubsection{Web Literacy}

Under this part of the curriculum, they were taught basics of designing a webpage, using software tools and optimization. Along with that they were taught what steps they could take to ensure being safe while they are connected to the internet, and were given an idea about what we can expect in the upcoming years from the area of technology.

\subsection{Revive the Art}

In today's market, the price range of a professional looking book covers lies between $\$ 20$ (INR 1,332) and $\$ 2000$ (INR 1,33,200) [2]. Since graphic designing has taken over the designing industry with a storm, the value of handmade art has been reduced. Hence, in this project, by combining the eloquent technique of graphic designing and beauty and grace of handmade art, we have tried to create a sustainable future for both Dot Org launched its own brand of notebooks (as shown in Fig.2), using the designs made by the children in the art classes, winter workshops, and competitions as the cover after digitally modifying them (Fig.1 [3]) printed. Two editions of the notebooks were launched under the name of "Sky is the Limit" and "Dare to Dream" [6]. A part of the total cost required for printing was sponsored by "Patronus" and the rest was paid by the contribution made by the team members.

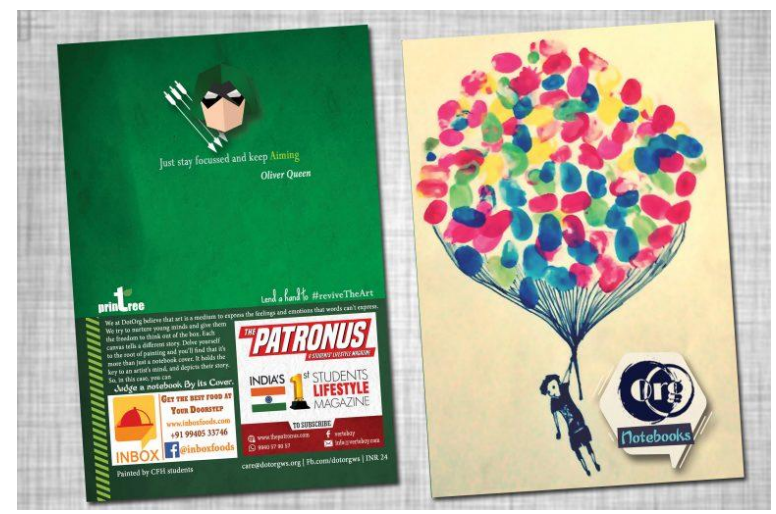

Fig.2 Digitally Modified Cover Designs

The target customers for the notebooks were the youth and the children. An online survey was conducted using Google forms to know the preference of the customers regarding the specifications of the notebooks like its dimensions, price, and number of pages, quality, importance of quality of pages, and importance of sponsors. The notebooks (Fig.1 [4]) were printed and the distribution and sales of the notebooks were conducted in Ramapuram, Chennai. 


\section{SCOPE}

Till now, the work done by the organization has made a lot of impact on the lives of children that they have taught. In the course of last two years, they have taken classes and have conducted workshops in many schools in major cities in states like Tamil Nadu, Delhi, West Bengal, and Maharashtra. The classes, which included topics such as art, soft skills, content writing, technology, web and internet, etc. are taught to make the children more aware about the present system and advancements.

In the future, the organization plans on manufacturing and selling the notebooks on a bigger scale and branch out to other states as well, all the while involving more NGOs, schools and collaborating with other organizations and people with similar interests who want to be a part of the cause. Further, they are planning on using encrypted notebook cover designs to cipher texts. Thus, making the covers interactive. The encrypted designs can be scanned through an app which will be developed by them and through that app the customers can scan the notebooks and decrypt the designs which will give them coupons and offers on goods or services. Along with that, they are also thinking of converting the paintings into gift wrappers which will be another way of bringing the work of children and artists into bright light.

\section{CONCLUSION}

The works that the organization has done has shaped the lives of many students. From the results that they got, it can be concluded that incorporating art and creativity into the methods of teachings not only helps in the development of the children, it also catapults their careers and chances of leading a meaningful and healthy life to another level. Addressing big challenges always do not require large efforts from big organization or government. Even various groups of like-minded people could come together to contribute in a meaningful way to address such problems.

\section{Journal Papers:}

\section{REFERENCES}

[1] Carl R. R. (1954). Toward a theory of creativity. ETC: A Review of General Semantics, 11, No. 4, 249260.

Books:

[2] Scarlet R. (2012). How much does a book cover cost? Retrieved on March 12, 2012 from http://booksat.scarlettrugers.com/bookcoverdesign/how-much-does-a-book-cover-cost/. News Article

[3] The Hindu. (2014), India has world's largest youth population: UN report. Retrieved on November 19, 2014 from http://www.thehindu.com/todays-paper/tp-in-school/india-has-worlds-largest-youthpopulation-un-report/article6612615.ece.

\section{Website}

[4] Mugdha, D. (2016). Creativity Takes Courage. Retrieved on September 2, 2016 from https://yourstory.com/2016/09/60ce4281a7-creativity-takes-courage/.

[5] Vignesh, K. (2016). Bringing younger minds closer to technology. Retrieved on December 11, 2016 from http://blog.dotorgws.org/2016/12/11/techyminds/.

[6] Uthra, R. (2017). What is \#reviveTheArt? Retrieved on January 12, 2017 from http://blog.dotorgws.org/2017/01/12/dotorgnotebooks/.

[7] P Bronson, A. M. (2010). The creativity crisis. Retrieved on July, 2010 from immagic.com 